\title{
PASADO, PRESENTE Y FUTURO DE LA REFORMA DEL DERECHO SOCIAL ESPAÑOL*
}

\author{
Manuel María Zorrilla Ruiz \\ Catedrático de la Universidad de Deusto
}

\section{Función de la reforma del Derecho Social}

Los juristas acostumbran a trivializar - con resonancias lúdicas a veces- dos nociones cuyo peso específico prevalece sobre otros elementos de su visión existencial del mundo del Derecho. Son ellas, las ideas de crisis y de reforma. La crisis significa la sustitución - no siempre superadora y ventajosa- de un estado de cosas - que ha consolidado un mínimo de disposición sistemática y principios rectorespor otro que ya no puede aprovecharse de estas adquisiciones. La crisis es algo más y distinto del mal de crecimiento, de la depresión recuperable o de la eventual contrariedad que sale al paso. Despierta la perplejidad, el desconcierto e incluso el pavor ante las manifestaciones de un cambio que - sin predecirse en lo que deben ser las líneas de fuerza de su definición - se intuye y termina por adivinarse. De ahí, que, a falta de ese cabal conocimiento, sea imposible o, cuando menos, harto aventurado, hacer un fidedigno diagnóstico de las finalidades historicosociales de la época o de las exigencias del momento en que, propiamente hablando, la crisis hace su aparición por vez primera.

Algo afín acontece con el concepto de reforma. Desde que su noción se presentó históricamente como la transformación de la cabeza y de los miembros de una institución caracterizada por la grandeza de su misión sobrenatural y la servidumbre de sus flaquezas humanas, la figura se predica de los cambios espectaculares o notables que sólo se

* Texto actualizado de la disertación académica que —invitado por la Asociación Argentina de Derecho del Trabajo y de la Seguridad Social que preside el Dr. Humberto A. Podetti, antiguo Magistrado y Procurador General del Trabajo- pronunció su autor, el 31 de mayo de 2000, en la sede de la ciudad de Buenos Aires (República Argentina). 
conciben en circunstancias de extraordinaria significación cultural, como las de la producción constitucional —que canonizó el elenco de los derechos universales e innatos - o las tareas codificadoras que, pese al impacto siguiente de los nacionalismos, erigieron un Derecho de corte universal.

Reformar es - hoy día y más aún en el sensible mundo del Derecho Social- adecuar, con máxima solicitud, las soluciones de las normas jurídicas a la intensidad y frecuencia de las demandas provenientes del cambio incesante de las realidades sociales. Ello significa un ...todo fluye... que contribuye a separar las reformas de las mudanzas legislativas demasiado complejas y de las operaciones domésticas de adecuación y retoque.

\section{Orientaciones constitucionales de la reforma del Derecho Social}

La consideración reformista del Derecho Social español arranca - con independencia del nivel de plenitud de sus compartimentos- de las reflexiones extraídas del texto constitucional.

Su Introducción o Preámbulo - cuya autoría, para sorpresa de muchos, no se debió al esfuerzo del legislador constituyente y sí a la contribución tardía de terceros con quienes, por imperativos del consenso, se condescendió excesivamente- no es, a causa de su radicalismo, un elemento contextual de interpretación de las normas jurídicas de Derecho Social. Cumple, más eficazmente, este papel el Título Preliminar que proclama la inauguración del Estado social y democrático de Derecho, confiere a los sindicatos un protagonismo pluridireccional y, a fin de promover la igualdad y la libertad efectivas, difunde el mensaje de la cláusula transformadora y social.

El espacio del conflicto industrial se hace coincidir con la zona más vasta y convulsiva del conflicto social, y, en razón de sus inconvenientes y ventajas, se defiende la normalización de las tensiones que, como naturales e irreprimibles, le son inherentes.

Se reitera el llamamiento a la utilidad del Derecho de Gentes y de cuantos compromisos supranacionales adquieren trascendencia para aplicar las normas jurídicas de Derecho Social.

Se reconocen, no sin alguna laxitud sistemática, la libertad sindical y el derecho de huelga como derechos fundamentales, pero se rebaja el nivel de protección de los derechos sociales individuales, y se reducen a principios programáticos -desprovistos de eficacia preceptiva directa- la garantía del régimen público de Seguridad Social y la promesa de orientar al pleno empleo la política social de la crisis. 
El repertorio de los principios rectores de la política social y económica revela la voluntad transformadora de acelerar — algo así como quemando etapas - el progreso de los grupos de la sociedad pluralista que reclaman atenciones de especial urgencia y cuya población mayoritaria consta de trabajadores dependientes.

Hay, en fin, una garantía - platónica y distante- de las expectativas de la democracia industrial y la participación.

Vienen al caso dos consideraciones. Una, la revigorización que acusan los derechos sociales a partir de una ingeniosa perspectiva de los derechos fundamentales a la igualdad material o no discriminación y a la efectiva tutela judicial. Otra, la revisión a que este enfoque se somete desde que, no hace mucho, se han registrado la emergencia y el reconocimiento textual de los novísimos derechos fundamentales en el espacio social europeo.

\section{Adecuación y ajuste constitucionales de las normas jurídicas de Derecho Social}

Un copioso acervo de las normas de Derecho Social emanadas del sistema autoritario - al que se deben muchas aportaciones en la materia-sufrió la prueba de depuración que, a falta de una presunción general de constitucionalidad del Derecho previgente, era obligado superar. Se constataba así que, al no oponerse a ninguno de los principios y/o preceptos constitucionales, quedaban integradas en el ordenamiento jurídico - recién inaugurado- que las asimilaba. Conseguían eludir una tacha - la de la impropiamente denominada inconstitucionalidad sobrevenida - que, amén de un desajuste constitucional, provocaría un vacío lesivo para la seguridad jurídica y perturbador de los intereses generales.

Esta técnica de salvamento trajo consigo la ventaja de no poner en el trance obsoleto de acudir — con los inconvenientes que ello suponía - a una salida emuladora de la que fue, en su día, la doctrina del uso alternativo del Derecho.

La efectividad de las normas de Derecho Social —adaptadas al sistema constitucional- se acrecienta por dos órdenes de razones interpretativas. Una, el manejo de los principios y/o preceptos constitucionales que, en unión de los criterios contextuales concretos, equivalen a elementos compartidos de interpretación de las normas que así se recobran. Otra, el dato de que las realidades sociales de cada lugar y cada tiempo —-definidoras de los ámbitos del Estado compuesto de las Autonomías - estimulan lecturas regionalizadas de la legislación estatal, 
que, más que operaciones hermenéuticas, constituyen innovaciones cuasilegislativas a cargo de los órganos del Poder Judicial.

\section{Significado politicosocial del Estatuto de los Trabajadores}

La promesa constitucional de un Estatuto de los Trabajadores alentó las ilusiones puestas en el modelo de legislación de apoyo que se proponía adjudicar a los pobladores del mundo del trabajo una posición jurídica inspirada en el mensaje de la cláusula transformadora y social.

De ello se habrían seguido muy estimables consecuencias. A saber, el reconocimiento y la tutela de los derechos fundamentales y las libertades públicas de los trabajadores en las unidades productivas, las garantías de la conmutatividad contractual frente a los excesos confiscatorios de las técnicas de racionalización, la cobertura intensificada y expansiva de las libertades sindicales en los lugares de empleo, el diseño imaginativo de las representaciones de los trabajadores en estas parcelas y la represión judicial de las conductas antisindicales. Las servidumbres del consenso postconstitucional mudaron el rumbo de la orientación y, en vez de cooperar a definir una nueva calidad profesional de vida, redujeron — con los aditamentos consiguientes - la novedad estatutaria a la prosaica regulación de la relación individual de trabajo.

El texto pactado dimanó de un juego de mutuas concesiones en lo individual y en lo colectivo. La mayoría parlamentaria pretendió atender a las aspiraciones del empresariado y regular la relación individual de trabajo en términos que -intuyendo el fenómeno de la crisis económica y augurando el advenimiento de la flexibilidad - reforzaban los poderes de organización y dirección. Las minorías de la oposición - políticamente comprometidas con los sindicatos de mayor audienciaconquistaron el reconocimiento de la representación unitaria en los centros de trabajo y la complaciente disciplina de apoyo a la negociación colectiva. Ante las dificultades de aplicación que se atisbaban, coincidieron en la necesidad de conservar - como Derecho supletorio rebajado a nivel reglamentario - la legalidad — técnicamente prestigiosa- del contrato de trabajo. Fracasó, en cambio, el propósito de cerrar una regulación exhaustiva del Derecho de conflictos, al impedirlo, de una parte, la exigencia de una ley orgánica para regular el derecho de huelga y la división de opiniones sobre su oportunidad, y, de otra, las discrepancias acerca de si el constituyente admitía tácitamente la figura del cierre patronal o si la falta de su mención nominativa reflejaba la intencionalidad de abolirlo. 
La moda - dominante en el curso de la transición democráticade privar a las leyes de Preámbulos o Exposiciones de motivos- para evitar dependencias demasiado severas de la voluntad de los legisladores y promover el uso del elemento historicoevolutivo de interpretación- afectó al texto estatutario, afanoso de que la aplicación de sus normas se abriese a la creatividad de las operaciones judiciales. La $\mathrm{Me}$ moria de acompañamiento al proyecto gubernamental — segregada del cuerpo definitivo de la ley- dio cabal idea de los objetivos a que la nueva regulación se enderezaba y contribuyó a esclarecer los aspectos básicos de su entendimiento.

Es de notar que la exigencia constitucional de una regulación legal del texto estatutario, incluye la obligación de atemperar sus normas a las realidades sociales sobrevenidas, independientemente de las predilecciones ideológicas que, en cada momento, cualifican a las iniciativas de legislación y de gobierno.

\section{Recepción y extensión de las libertades sindicales}

Una de las consignas preconstitucionales - asumida desde el amanecer de la transición democrática-consistió en incorporar al modelo del Estado social y democrático de Derecho que se proyectaba, los textos supranacionales que reconocían las libertades sindicales.

Pese a lo elogiable de este esfuerzo, las perspectivas constitucionales y legales de la libertad sindical se resienten de un tratamiento asistemático. El constituyente ha dispersado, sin demasiado esmero, en pasajes distintos y distantes, las expresiones colectivas de esa libertad, los contenidos peculiares de su naturaleza individual y la garantía de apoyo a la negociación colectiva. La legislación estatutaria — derivada de la promesa constitucional y pensada para reforzar el Derecho de las relaciones individuales de trabajo - terminó acogiendo, por imperativos del consenso, las variantes de aquella libertad que incluían las formas de representación unitaria en los lugares de trabajo y la ordenación estructural de los convenios.

Las pretensiones de la democracia industrial y del acceso a la propiedad privada de los instrumentos y medios de producción ocuparon un espacio constitucional que, para aliviar la tarea del legislador ordinario y facilitar la movilidad de su decisionismo político, quedaba fuera del elenco de las libertades sindicales.

A diferencia de otras libertades y derechos constitucionales que el legislador estaba obligado a plasmar, sin dilación, en normas jurídicas obligatorias, la regulación legal de la libertad sindical no era constitu- 
cionalmente inexcusable. Ello no obstante, su tratamiento legislativo se llevó al mejor fin para probar la efectividad y no sólo el testimonio enfático del esfuerzo social transformador. Tras haber sorteado los entorpecimientos del recurso previo de inconstitucionalidad contra los proyectos de leyes orgánicas - cuya supresión posterior fue acogida con general satisfacción - se advino a un resultado que, aunque dotaba de adquisiciones positivas, no estaba exento de reparos. Las primeras supusieron la ampliación conceptual de la idea de trabajador, la promoción de la acción sindical en la empresa, la recepción de la figura del sindicato más representativo y la represión judicial de los comportamientos antisindicales. Debe, al contrario, censurarse la inmunidad que de hecho ha conquistado el sindicato frente a las exigencias de responsabilidad por daños derivados de sus actuaciones abusivas o ilícitas.

Es de notar cómo la justicia constitucional comenzó auspiciando la idea pluridireccional de una libertad sindical que, más allá de las definiciones típicas y tópicas del Derecho de Gentes, legitimaba al sindicato para diagnosticar y defender cuantas demandas sociales requiriesen atención y remedio. No es acertado el parecer - restrictivo y científicamente criticable - de que esa justicia ha echado mano para rehusar a los órganos de representación unitaria en los lugares de trabajo el carácter de titulares de las libertades sindicales $\mathrm{y}$, con base en este prejuicio conceptual, denegarles la protección del recurso de amparo constitucional.

\section{Tratamiento del derecho de huelga}

El reconocimiento del derecho fundamental a la huelga introduce una medida de apoyo que, como opciones indistintamente constitucionales, admite la de su regulación legislativa y la de su autorregulación sindical. La primera de ellas obliga a ordenar el modelo contractual - variante de presión institucionalizada que contrapesa los poderes empresariales de organización y dirección - y el de la huelga testimonial que, con el límite impuesto por el desencadenamiento de la huelga política, reprueba el comportamiento de los poderes oficiales, para modificarlo, o aspira a provocar determinadas reacciones de la opinión pública.

La nonnata reforma promovida para conjurar las deformaciones antisociales y abusivas de la huelga, registró la metamorfosis alarmante a que, en el curso del trámite parlamentario de elaboración de la ley, dieron lugar la radicalización y el antagonismo de las posturas políticas y sindicales. Desistiéndose de la perspectiva de una legislación discretamente disuasoria, pasó a canonizarse una regulación excitante al ejer- 
cicio del derecho de huelga. Desnaturalizados sus objetivos y alejado de su justificación originaria, el texto proyectado achicó los supuestos de huelga ilegal, suprimió la causa de despido derivada de su participación en la misma, legalizó la ocupación de los lugares de trabajo, abordó permisivamente la intervención de los piquetes y traslado el control de los servicios mínimos a los agentes sindicales directamente interesados en su desmesurada restricción.

La intuición de las pésimas consecuencias de semejante idea, determinó que un adelanto intencional —díjose que pactado entre los empresarios y el Gobierno- de la convocatoria de elecciones generales, frustrase la aprobación del proyecto.

\section{Aplicación de las normas del sistema de la Seguridad Social}

El ordenamiento constitucional importó, por modo de adecuación sobrevenida, la regulación previgente del sistema de la Seguridad Social, que paradójicamente devino un desarrollo preconstitucional del principio rector que garantizaba el mantenimiento de su régimen público. Su aplicación y entendimiento se tornaron cíclicamente regresivos.

El mantenimiento de aquel régimen se contrajo a conservar su estructura formal y no a promover la subsistencia del principio de irregresividad. Los destinatarios de las normas del sistema dejaron de ser titulares de derechos adquiridos — despojados de lo sólido de esta condición-y portadores de las expectativas depositadas en lo creciente y perdurable de sus consignas de irretractabilidad y de progreso. Se convirtieron en pacientes de una política de redistribución legislativa de auxilios sociales que, escudada en el difuso impacto de la solidaridad, auguraba la multiplicación cuasibenéfica de la tutela asistencial y conminaba con la escasez y aún con la desaparición de la protección contributiva. La suficiencia de las prestaciones dejó de restaurar la dosis de bienestar perdida a causa de cualquier contingencia y prefirió paliar módicamente la magnitud del malestar sufrido. En vez de procurar un razonable acercamiento a la cuantía de las rentas dejadas de obtener, la suficiencia simbolizó el impedimento a la caída en la sima de la marginación y la pobreza. Lejos de esforzarse en afianzar la continuidad de las prestaciones sociales, los responsables políticos insistieron - con terquedad apocalíptica que disimulaba sus más graves pecados mortales - en la bancarrota del sistema protector y predijeron su disolución a medio plazo.

El abuso de la legalidad presupuestaria —utilizada como el cajón de sastre que sorprende con los rebotes más inesperados en distintos 
sectores del ordenamiento jurídico- propició las operaciones regresivas de rebaja y confiscación de las pensiones públicas. La justicia constitucional, lejos de enmendar ese estado de cosas, le santificó y estimó acorde con las pautas de solidaridad que, sin cauces de control eficaz, podían informar las decisiones soberanas del Estado-legislador.

Dominaba la impresión subliminal de que, para adiestrar a los agentes sociales en las tareas protectoras de la comunidad, el Estado debía desentenderse de algunas de esas cargas e invitar a familiarizarse con fórmulas complementarias de aseguramiento.

Está por ver cómo ha de producirse y cuál será la reacción de los poderes públicos frente a la reserva de Directiva que - ante la elevación del derecho a la Seguridad Social al rango de derecho fundamental-compete a la Comisión comunitaria en una materia que no puede seguir castigada por los arbitrismos reductores de los Estados miembros.

\section{Emergencia tardía de la flexibilidad}

Una ulterior reforma estatutaria acogió — con una demora de más de cuatro lustros respecto a las novedades de las democracias industrializadas con economía de mercado- las consignas de la flexibilidad y la desregulación que, a cambio de recrear las funciones sociales de la libertad de empresa y detener la destrucción del empleo, liquidaron el inconmovible principio de irregresividad de las adquisiciones sociales. De este cambio de rumbo se siguió la conversión en Derecho dispositivo de no pocas normas que hasta entonces acampaban en los pagos del Derecho necesario.

Cierto que, a requerimiento de los sindicatos, la reforma introdujo elementos compensatorios de estabilidad, eliminando las variantes de contratación temporal que no requerían la justificación de causa extintiva - destinadas, bajo distintas rúbricas, al común objetivo del fomento de empleo - y la contratación propia de las reconversiones industriales que inauguraban ciclos productivos inéditos.

El tratamiento flexible de las relaciones individuales de trabajo se reflejó en la privatización del mercado de empleo, dando entrada a las agencias particulares de colocación y a las empresas de trabajo temporal, en la liberalización de los despidos individuales — limitando la declaración de nulidad al supuesto de vulneraciones constitucionales y añadiendo causas de extinción fundadas en la crisis de empresa- y en la atribución de carácter dispositivo a las normas rectoras de la jornada de trabajo, los salarios y la modificación de las condiciones de empleo. 
La negociación colectiva se flexibilizó, reemplazando una parte, que se ha acrecentado con el tiempo, de sus contenidos inderogables de orden público por el resultado del ejercicio autónomo de la voluntad individual. La llamada disolución del conflicto industrial (¿?) se relaciona significativamente con los resultados de estas experiencias y con el debate eticojurídico sobre sus atisbos de perversidad.

\section{Cumplimiento de la deuda de seguridad}

La alarmante frecuencia estadística de los accidentes de trabajo ha justificado que, con independencia de la acción protectora del régimen público de Seguridad Social, se atienda especialmente a este aspecto de la deuda de seguridad del empleador. No en vano, los derechos a la vida y a la integridad física - rejuvenecidos por algunos de los principios constitucionales que informan la política social y económicason derechos fundamentales con cuya defensa se comprometieron siempre las organizaciones supranacionales de producción del Derecho Social y las normas europeas del Derecho Comunitario derivado.

El deber de protección es progresivo, obligatoriamente acomodado al cambio de las circunstancias y exclusivamente imputable a la economía empresarial. Su acervo - que comprende la evaluación de los riesgos, el sistema de consultas, y las acciones de planificación, documentación y vigilancia - se completa con el establecimiento de responsabilidades penales, civiles y administrativas, y se afianza con los nuevos mecanismos de participación de los trabajadores en la acción preventiva.

Sorprende lo defectuoso de la tesis que la jurisprudencia ordinaria ha adoptado sobre la reclamación del importe de las diferencias económicas entre la magnitud de la reparación íntegra del daño causado y la de otras percepciones - de inferior cuantía - que resarcen la pérdida o el menoscabo de la vida y/o la integridad física del trabajador. Se defiende, con frágil discurso, que esa peripecia de la deuda de seguridad no constituye un episodio patológico de la relación individual de trabajo y que se encuentra al margen de ella. Como si, en virtud de una ficción esotérica, el empresario y el trabajador nunca hubiesen mantenido la comunicación que les ligaba desde la formación del contrato y - desoyendo el dictado del principio ontológico de no contradicción- se hubiesen ignorado recíprocamente hasta la ocurrencia del hecho dañoso. De ahí, la conclusión ilógica de que aquella reclamación es de índole extracontractual y de que su conocimiento no compete al orden social de la jurisdicción y sí a los órganos del orden civil. 


\section{Innovaciones recientes}

La etapa más reciente se caracteriza por la toma de decisiones económicas que, lejos de servir de coartada para degradar la protección social, tienden a reducir las tasas de desempleo, conservar el poder adquisitivo de las rentas de trabajo y desactivar las lastimosas condiciones del régimen público de Seguridad Social, cuya desaparición habían predicho, sin una tilde de recato, ciertos voceros oficiales.

No han entrañado acciones de reforma - técnicamente hablandolos acuerdos relativos a la cobertura de vacíos y a la negociación colectiva, que robustecieron la soberanía sindical de las organizaciones firmantes, ni las novedades legislativas que modificaron la contratación a tiempo parcial y abordaron los aspectos relevantes de la vida personal y familiar de las personas trabajadoras.

\section{1. ¿Perspectivas de un Derecho Social Autonómico?}

El Derecho de las relaciones de trabajo se debe al ejercicio de una competencia exclusiva del Estado, porque su formación gradual no ha sido el fruto de la fusión o remodelación de unos Derechos regionales - de ámbito territorial menos amplio- cuya inexistencia histórica invalida la hipótesis de un ciclo integrador de este carácter. Aquel Derecho aporta al sector correspondiente del ordenamiento jurídico los hallazgos y avances de un depósito de Derecho de Gentes fogueado por el desafío de los movimientos sindicales, racionalizado por los organismos supranacionales — que asimilan técnicamente sus adquisicionesy positivizado por el legislador del Estado social y democrático de Derecho. Ello no ha disuadido de ensayar, con base en soluciones de aproximación, la especie de un Derecho Social en las Comunidades Autónomas que forman el todo del Estado compuesto.

Las competencias legislativas autonómicas pueden alcanzar a las materias mixtas que — como la verificación y normalización de las peripecias del conflicto industrial- no sólo comprometen la intervención del Estado-legislador en cuestiones sociales, sino que también atañen a la porción de paz social o de orden público en que la potestad estatutaria de autogobierno se manifiesta y repercute.

Cabe asimismo que los poderes centrales transmitan a las autonomías competencias que, concerniendo a materias de Derecho Social, sean por naturaleza susceptibles de transferencia irrevocable o de delegación controlada y reversible. Resulta inaceptable, por evidencia histórica, el supuesto de la retrocesión o rescate de unas competencias 
que, al no haber existido nunca en los espacios regionales o autonómicos, mal han podido ejercitarse y difundirse en ellos.

El Derecho estatal de las relaciones de trabajo adquiere grados variables de autonomización si - para exhumar el espíritu y finalidad convenientes a su aplicación judicial o extrajudicial- las realidades sociales de cada lugar y cada tiempo aconsejan operaciones interpretativas que equivalen a tareas de cuasilegislación correctora.

La reivindicación de un marco autonómico de relaciones de trabajo - favorecedora de la confusión de la autonomía sindical con las condiciones de la autonomía politicoadministrativa - obedece a criterios que no han sabido deslindar sus dimensiones políticas de los elementos individualizadores de la estructura de la negociación colectiva.

\section{Fenomenología de las decisiones de la justicia constitucional}

Resultan sorprendentes ciertas expresiones fenomenológicas de la acción de la justicia constitucional en el campo del Derecho Social y las consecuencias reformadoras que de su intervención se han seguido.

Los controles de vulneración de derechos fundamentales - específicos de los recursos de amparo en las controversias de Derecho Social- prevalecen estadísticamente sobre los procedentes de otros sectores del ordenamiento jurídico. Lo copioso de la contribución ha dotado a la justicia constitucional de una materia prima inestimable para construir la doctrina relativa a los derechos fundamentales y las libertades públicas. El conocimiento y la aplicación del Derecho Social son, a su vez, inconcebibles sin el complemento que esas adquisiciones reportan. Algunas de ellas, muy interesantes.

Un ingenioso enfoque de los conflictos de Derecho Social — desde la perspectiva de los derechos fundamentales a la no discriminación y a la efectiva tutela judicial de los derechos subjetivos e intereses legítimos de todas las personas - ha cooperado a suplir la insuficiencia del depresivo enclave sistemático de los derechos sociales en el texto constitucional.

Tampoco es infrecuente que, sobrepasando el ámbito de la legalidad constitucional, se den invasiones e ingerencias en el campo de la legalidad ordinaria, cuya exclusiva aplicación incumbe a los órganos del orden social de la jurisdicción.

Desbordándose, a veces, los límites de la casación cuasiconstitucional, se ha privado a los jueces ordinarios - competentes para entender del fondo del asunto- de dictar la nueva sentencia que, tras la estimación de un recurso de amparo, debían pronunciar en sustitución de la resolución anulada. 
El recurso de inconstitucionalidad contra normas jurídicas con rango de ley, se ha utilizado para ir más lejos de las funciones específicas de la legislación negativa y actuar como legislador positivo que, en vez de limitarse a expulsar las normas jurídicas inconstitucionales del sector social del ordenamiento jurídico, introduce alguna que otra de propia cosecha.

\section{Unificación judicial del Derecho Social}

Una materia tan elástica como la continente de las normas del Derecho Social, requiere atender a las transformaciones -formales e informales-que se siguen de sus experiencias de aplicación judicial.

La acción depuradora de los principios y preceptos constitucionales afectó a la regulación previgente del proceso en materia de Derecho Social, cuyas ventajas y excelencia - respecto al modelo de proceso clásico- se habían puesto de relieve. Sus líneas de fuerza - obedientes a la oralidad, la inmediación y la concentración de los actos procesales - se ajustaron a los imperativos de la legalidad fundamental, más fácil y flexiblemente que las envejecidas normas del proceso escrito, mediato y preclusivo. Su codificación definitiva ha recibido, además de estos datos, las aportaciones con que la justicia constitucional ha tenido a bien contribuir.

No se han requerido reformas de calado muy hondo y ha bastado un esfuerzo de mínimo esmero para que la codificación procesal en materia social cumpla los postulados de una efectiva tutela judicial. De ahí, la celeridad de las respuestas obtenidas y la ausencia de dilaciones indebidas que, a diferencia de otros órdenes jurisdiccionales, registra ese campo de la Administración de Justicia.

La unificación jurisprudencial del Derecho Social no engendró problemas mientras la competencia de los órganos que entendían de los recursos extraordinarios se correspondía con la vigencia territorial del Derecho del Estado entonces aplicado. La actual coincidencia del control unificador con el marco geográfico de las Comunidades Autónomas, muestra lo inevitable de unas contradicciones que, a mayor abundamiento, no son fácil y fidedignamente comprobables. De ahí, la dificultad de aminorarlas mediante las peculiaridades de una fórmula que, calcada del viejo recurso en interés de ley, explica la ausencia de los efectos satisfactorios que convienen a la bondad nomofiláctica de los resultados queridos. Puede darse incluso la especie de inconstitucionalidad sobrevenida que se aprecia al verificar 
la inutilidad estadística del recurso pensado para unificar un sector del ordenamiento jurídico que pese a todo, se ve fraccionado por irreductibles divergencias interpretativas.

\section{Futuro inmediato y trascendencia jurídica de la política social}

La reforma de los aspectos de la política social que convienen al programa política postelectoral, cuenta con el favor de una sintonía estimulante e infrecuente. La que debe sobrevivir, dados los precedentes de una sana comunicación, entre los agentes políticos - cuya es la decisión propia de los actos de legislación y de gobierno- y las organizaciones sindicales. El grado de aproximación de ambas comunidades disipa los obstáculos a las actitudes civilizadas y de diálogo - compatibles con la conservación de los idearios e identidades respectivas - y les hace primar sobre las álgidas posturas de confrontación que comúnmente acompañan a los contactos de esa naturaleza.

Aunque es prematuro sistematizar, por intuición o advertencia precoz, el signo de esa política social, parece que, en vez de cambios espectaculares, se percibe - como ocurre con las revoluciones emprendidas y consumadas gota a gota - la voluntad de algunas decisiones notables.

La precariedad del empleo constituye un mal social que clama por su eliminación. No se trata de retornar - aunque los nominalismos enturbien la comprensión de los términos del debate- al principio de estabilidad en el empleo, perteneciente al ayer de la plena ocupación de las sociedades prósperas, y sí de adjudicar un rostro humano al hoy del principio de continuidad en el empleo. Es éste el mal menor y razonablemente admisible en las comunidades recorridas por la crisis económica, obligadas a repartir el empleo, y apremiadas por la inevitabilidad de las reconversiones industriales y la necesidad complementaria de la readaptación profesional - comprensiva de las acciones de formación y perfeccionamiento- de los trabajadores.

Una síntesis de remedio para lo irremediable pretende recurrir al régimen de contratación estable a tiempo parcial, que, a cambio de reducir la extensión del trabajo aceptado por los demandantes de empleo, mitiga los inconvenientes de la precariedad a tiempo completo, aunque no salvaguarda los aspectos centrales del derecho constitucional al trabajo. Queda sin resolver el problema de armonizar la parcela de las contrataciones temporales - acogida al principio de continuidad en el empleo- y la dosis de contratación indefinida que, sin merma del con- 
tenido esencial de la libertad de empresa y de sus recientes funciones sociales, tolera la economía de cada proceso productivo.

La protección del derecho constitucional al trabajo tropieza con consecuencias indeseadas que, a causa de las crisis de empresa, determinan el abandono anticipado de la población activa. Sucede así cuando, sin mediar situaciones de necesidad insuperable, se aminoran, por motivos de simple conveniencia, las cargas económicas de un ciclo productivo que, gracias a ese alivio, registra un aumento sensible y quizás excesivo de su rendimiento. Situaciones antisociales que, en cada circunstancia, hay que cribar para evitar su repetición en el futuro.

Hay que rectificar la propensión que, por obra de la indiferencia y el desentrenamiento sindicales, denota una negociación colectiva tendente a mejorar adquisiciones que - cuales las relativas a los salarios y a la jornada de trabajo - reflejan las culturas del consumo y del ocio. Esa negociación orilla, en cambio, los objetivos de calidad que - como la participación, la defensa colectiva y la promoción del empleo, la garantía de las libertades sindicales, la institucionalización de las correspondientes representaciones y los problemas de la deuda de seguridad empresarial- condensan las reivindicaciones cuya perfección determina la elevación de los trabajadores al rango de ciudadanos ilustrados, responsables y libres.

No hay que perder de vista la repercusión de la falta de una política de rentas en la caracterización de la economía general, cuyas exigencias son una de las claves de la protección de la productividad encomendada a los poderes públicos.

La flexibilización del mercado de trabajo ha impuesto las empresas de trabajo temporal que, aunque justificadas en un sistema dúctil de relaciones industriales, precisan mecanismos garantizadores de los derechos de los trabajadores que, en ese trance, no siempre corren la mejor de las suertes.

La protección de la vida y la seguridad física de los trabajadores sigue siendo un objetivo denunciado por los alarmantes índices de siniestralidad que el hecho productivo revela. Habida cuenta de los parcos efectos que asegura la intervención de vigilancia, es preciso disponer de un inventario de prevención de riesgos que traslade al coste de la cobertura de la acción profiláctica los recursos, que, en los casos de resultado irreversible, resarcen los daños causados por los accidentes de trabajo.

La protección del sistema de la Seguridad Social tiene que armonizar la solidaridad — que no es un absoluto disolvente de la individualidad de los derechos adquiridos- con la suficiencia de las prestaciones 
sociales. Además de los problemas técnicos de financiación que hay que afrontar, no es menos urgente el tratamiento de ciertos aspectos jurídicos de constitucionalidad.

Estas y otras reformas de análogo calibre inducen a reflexionar algo más. Si el sindicato se ha erigido de antiguo en colegislador de hecho, el parlamento debe — sin abdicar de su soberanía lo más mínimo-frecuentar y sacar provecho del inteligente experimento de las leyes pactadas. Sólo así se acredita el éxito de las iniciativas sindicales que materialmente se ingieren en el proceso formal de elaboración de las normas de Derecho Social. Otra indicación —en la que vale la pena insistir- atañe a la cuestión del ascenso de los derechos sociales a la categoría de derechos fundamentales en la Europa Comunitaria.

\section{Conversión de los derechos sociales en derechos de carácter fundamental}

El fenómeno de la emergencia y el reconocimiento de los nuevos derechos fundamentales en el espacio social europeo no está exento de repercusiones en el plano constitucional. Cuando los textos comunitarios más recientes atribuyen a los derechos sociales la cualificación de derechos fundamentales, ejercitan una opción conceptual con la que se comprometen de manera inequívoca y no frívola. Lo fundamental no puede adquirir — si se es fiel al principio ontológico de no contradicción- en el ordenamiento jurídico comunitario un significado distinto del que le asigna la tradición juridicopolítica de los Estados miembros de la Unión Europea.

Se pregunta si esta sugestiva novedad afecta al ordenamiento constitucional que, luego de haber reconocido como derechos fundamentales la libertad sindical y el derecho de huelga, rebaja el derecho al trabajo a un mero derecho de la ciudadanía y no pasa de enunciar una orientación programática para el régimen público de Seguridad Social.

Es de desear que, desde ya, el poder judicial del Estado aplique las normas de Derecho Social conforme al principio de primacía del Derecho Comunitario, de suerte que - mejorando la calidad de los derechos y principios sociales deprimidos por el legislador constituyente- reciban éstos el trato efectivo de derechos fundamentales que aquel ordenamiento les confiere.

Las reacciones individualizadas no eximen de las operaciones necesarias para trasladar — mediante la oportuna reforma - al pasaje constitucional que incluye la lista de los derechos fundamentales y las liber- 
tades públicas, los preceptos y principios que —en materia de Derecho Social - han extravagado del mismo hasta adquirir la condición óptima que se les acaba de otorgar.

El acceso a la tierra prometida de la Europa social levanta un nuevo testimonio — sincero y, a la par, tardío - frente a la invasión de las corrientes neoliberales y su ineptitud para garantizar la administración acertada de un fenómeno globalizador que, tarde o temprano, se les irá escapando de las manos. Poco hay de nuevo en la esencia de esta concepción que, de antiguo y con miras moralizadoras, encendió las curiosidades del realismo filosófico y alimentó las denuncias proféticas de los reformadores sociales. Impresionados, todos ellos, por las perspectivas - retadoras y optimistas para la causa de la dignidad humanade la que, muy sagazmente, ya entonces se intuía como incoación del fenómeno del achicamiento del mundo. 